\title{
KERAGAAN EKSISTING TANAMAN AREN (Arenga pinnata Merr) DI SUMATERA UTARA (Peluang dan Potensi Pengembangannya)
}

\section{Lukas Sebayang}

Balai Pengkajian Teknologi Pertanian Sumatera Utara

*Corresponding author : mabayang2001@yahoo.com

\begin{abstract}
Sugar palm (Arenga pinnata, Merr) is the most important after the coconut because it is a versatile crop that has the potential to be developed. Sugar palm main products are produced from extracting male flower it can be made as sugar, drinks, acetic and alcohol. Other parts of the plant can be use for ingredient. Data from 2004 shows sugar palm plantation covers 5288.91 acres that are spread in 20 districts in North Sumatra. Utilization sugar palm excellent for especially extracting products can be used as feedstock for ethanol as the needs of the bioenergy development will need to be followed up. Opportunities and potential development in North Sumatra palm is huge in because ecosystems, climate and suitability of land in this area is very suitable for the sugar plant. Opportunities and potential development sugar palm in North Sumatra is very large in because ecosystems, climate and suitability of land in this area is very suitable for the sugar palm plant. Besides adaptable to various types of soils including degraded lands, reeds and for reforestation and forest conservation . Data in 2014 , there is the land area is temporarily not cultivated in North Sumatra tend to rise until 2013, covering an area of 296032 ha . Another challenge than land development, are super - impose intesifikasi input technology is still minimal, improvement of production management, improved processing, marketing is still traditional, dissemination is still limited to a small proportion of farmers, and the difficulty of seeds. So, we need a shared commitment between the central government and local governments to create policies how the potential development of the sugar plant can be followed in the future. This paper reviews the prospects of development potential, especially palm acreage potential, opportunities and challenges as well as the availability of the technology in North Sumatra.
\end{abstract}

Keywords : Arenga pinnata, performance, existing, North Sumatera.

\section{ABSTRAK}

Aren atau enau (Arenga pinnata, Merr) adalah palma yang terpenting setelah kelapa (nyiur) karena merupakan tanaman serba guna yang mempunyai potensi untuk dikembangkan. Produk utama tanaman aren sebagai hasil dari penyadapan nira bunga jantan dapat dijadikan gula, minuman, cuka dan alkohol. Selain itu bagian tanaman yang lain dapat dibuat bahan makanan. Pada tahun 2014 tercatat luas areal tanaman aren 5.288,91 hektare tersebar di 20 kabupaten di Sumatera Utara. Melihat prospek pemanfaatan aren sangat baik kedepan terutama produk nira aren dapat dijadikan bahan baku etanol sebagai kebutuhan bioenergi maka pengembangannya perlu segera ditindaklanjuti. Peluang dan potensi pengembangkan aren di Sumatera Utara sangat besar di karenakan ekosistim, iklim dan kesesuaian lahan yang ada di daerah ini sangat sesuai untuk tanaman aren. Selain mudah beradaptasi pada berbagai tipe tanah termasuk lahan kritis, alang-alang dan untuk reboisasi dan konservasi hutan. Data tahun 2014 luas areal lahan yang sementara tidak diusahakan di Sumatera Utara cenderung naik sampai tahun 2013 seluas 296.032 ha. Sedang tantangan lain selaian lahan pengembangan, intesifikasi secara super-impose input 
teknologi masih minim, perbaikan manajemen produksi, perbaikan pengolahan, pemasaran masih tradisional, diseminasi masih terbatas pada sebagian kecil petani, dan kesulitan bibit unggul. Sehingga diperlukan komitmen bersama antara Pemerintah pusat dan Pemerintah Daerah untuk membuat kebijakan bagaimana potensi pengembangan tanaman aren ini bisa ditindaklanjuti kedepannya. Tulisan ini mengulas prospek potensi pengembangan aren terutama potensi areal, peluang dan tantangan serta ketersediaan teknologi di Sumatera Utara.

Kata kunci : Arenga pinnata, keragaan, muncul, Sumatera Utara.

\section{PENDAHULUAN}

Siapa kini yang tak kenal pohon aren atau enau (Arenga pinnata Merr), merupakan pohon jenis palma yang terpenting setelah kelapa (nyiur). Pohon aren memiliki potensi ekonomi yang tinggi karena hampir semua bagiannya dapat memberikan keuntungan finansial, dimana seluruh bagian tubuhnya bisa dimanfaatkan. Dari daunnya, kita bisa membuat sapu lidi atau lidi pincuk, batangnya untuk penyangga rumah, pelepahnya (ijuk) bisa untuk atap rumah, gula dan minuman tuak/segar (fresh drink), buahnya menghasilkan kolang-kaling (Ramadhani 2015). Air batangnya menghasilkan nira yang kemudian sering diolah menjadi bioetanol bahan pengganti bahan bakar minyak (Smith 2014). Akarnya serabut melebar merekat kuat ke bahan tanah sangat baik sebagai penahan erosi dan longsor (tanaman konservasi : rehabilitas dan reboisasi) serta kemampuannya menyerap $\mathrm{CO}_{2}$ dalam jumlah banyak mendukung mitigasi gas rumah kaca sehingga dapat menekan pemanasan global. Tanaman aren menghasilkan biomas di atas tanah dan dalam tanah yang sangat besar sehingga berperan penting dalam siklus $\mathrm{CO} 2$ (Syakir dan Effendi, 2010). Selain itu tanaman aren dapat menghasilkan produk makanan dari buah betina yang sudah masak dan tepung aren untuk bahan pembuatan kue, roti dan biskuit yang berasal dari pengolahan bagian empelur batang tanaman (Alam dan Baco, 2004; Maliangkay et al., 2004)

Pohon enau dapat mencapai $25 \mathrm{~m}$. Berdiameter hingga $65 \mathrm{~cm}$, batang pokoknya kukuh dan pada bagian atas diselimuti oleh serabut berwarna hitam yang dikenal sebagai ijuk, injuk, juk atau duk. Ijuk sebenarnya adalah bagian dari pelepah daun yang menyelubungi batang. Daunnya majemuk menyirip, seperti daun kelapa, panjang hingga $5 \mathrm{~m}$ dengan tangkai daun hingga $1,5 \mathrm{~m}$. Anak daun seperti pita bergelombang, hingga 7 x $145 \mathrm{~cm}$, berwarna hijau gelap di atas dan keputih-putihan oleh karena lapisan lilin di sisi bawahnya (Soeseno 1991).

Pohon aren merupakan pohon berumah satu, bunga-bunga jantan terpisah dari bunga-bunga betina dalam tongkol yang berbeda yang muncul di ketiak daun; panjang tongkol hingga $2,5 \mathrm{~m}$. Buah buni bentuk bulat peluru, dengan diameter sekitar $4 \mathrm{~cm}$, beruang tiga dan berbiji tiga, tersusun dalam untaian seperti rantai. Setiap tandan mempunyai 10 tangkai atau lebih, dan setiap tangkai memiliki lebih kurang 50 butir buah berwarna hijau sampai coklat kekuningan. Buah ini tidak dapat dimakan langsung karena getahnya sangat gatal (Sunanto 1992).

Secara ekologi dan penyebaran, pohon aren mudah tumbuh. Memiliki asalusul dari wilayah Asia Tropis, aren diketahui menyebar alami mulai dari India Timur di sebelah Barat, hingga sejauh Malaysia, Indonesia dan Filipina di sebelah Timur. Di Indonesia, aren tumbuh liar atau ditanam sampai ketinggian $1.400 \mathrm{~m}$ dpl. Biasanya banyak tumbuh di lereng-lereng atau tebing sungai (Heyne 1987).

Bagi sebagian masyarakat Sumatera Utara yang berada di desa, pohon aren adalah sumber penghidupan yang dapat 
diandalkan dalam membantu ekonomi keluarga. Umumnya pohon aren di daerah ini tumbuh secara alami dan masih sedikit dibudidayakan. Di Provinsi Sumatera Utara, hampir setiap kabupaten terdapat pohon aren. Tulisan ini mengulas prospek potensi pengembangan aren terutama potensi areal, peluang dan tantangan serta ketersediaan teknologi di Sumatera Utara.

\section{PROFIL TANAMAN AREN}

\section{Deskripsi}

Tanaman aren menurut klasifikasi tanaman dimasukkan dalam divisi Spermatophyta, subdivisi Angiospermae, kelas Monocotyledonae, bangsa Spadicitlorae, suku Palmae, marga Arenga dan jenis Arenga pinnata MERR. Tanaman ini tumbuh pada beberapa daerah dengan nama yang berbeda. Di Aceh diberi nama Bakjuk, Batak Karo dinamai Paula, Nias diberi nama Peto, Minangkabau nama Biluluk, Lampung nama Hanau, Jawa Tengah diberi nama Aren, Madura nama Are dan di Bali nama Hano. Untuk Nusa Tenggara diberi nama : Jenaka, Pola, Nao, Karodi, Moka, Make, Bale dan Bone. Pemberian nama tanaman ini untuk Sulawesi: Apele, Naola, Puarin, Onau, dan Inau. Sedang untuk kepulauan Maluku diberi nama: Seko, Siho, Tuna, Nawa dan Roni. (Rindengan dan Manaroinsong 2009 ).

Saat ini telah tercatat ada empat jenis pohon yang termasuk kelompok aren yaitu : Arenge pinata (Wurmb) Merr, Arenge undulatitolia Bree, Arenge westerhoutii Grift dan Arenge ambcang Becc. Diantaranya keempat jenis tersebut yang sudah dikenal manfaatnya adalah arenge piñata, yang dikenal sehari-hari dengan nama aren atau enau.

Penggolongan jenis aren berdasarkan umur mulai menghasilkan, bisa dikategorikan menjadi 3 (tiga) jenis, yaitu : (1) Aren Genjah, umur mulai menghasilkan antara 4, 5 atau 6 tahun (dibawah 6 tahun).
(2)Aren Sadang, umur mulai menghasilkan antara 7, 8 atau 9 tahun. (3)Aren Dalam, umur mulai menghasilkan setelah umur 10 tahun (Kusumanto 2012).

Tanaman aren sesungguhnya tidak membutuhkan kondisi tanah yang khusus (Hatta- Sunanto 1982) sehingga dapat tumbuh pada tanah-tanah liat, berlumur dan berpasir, tetapi aren tidak tahan pada tanah yang kadar asamnya tinggi ( $\mathrm{pH}$ tanah terlalu asam). Aren dapat tumbuh pada ketinggian 9 - 1.400 meter di atas permukaan laut. Namun yang paling baik pertumbuhannya pada ketinggian 500 - 800 meter di atas permukaan laut dengan curah hujan lebih dari $1.200 \mathrm{~mm}$ setahun atau pada iklim sedang dan basah menurut Schmidt dan Ferguson.

Berdasarkan habitus tanaman; pohon aren berdiri tegak dan tinggi, berbatang bulat warna hijau kecoklatan, daun terbentuk dalam reset batang dengan anak daun menyirip berwarna hijau muda/tua, bunga terdiri atas bunga jantan yang menyatu dalam satu tongkol ukuran panjang 1- 1,2 $\mathrm{cm}$. Bunga betina pada tongkol yang lain bentuk bulat yang terdiri atas bakal buah tiga buah, warna kuning keputihan. Buah yang telah terbentuk berbentuk bulat panjang dengan ujung melengkung ke dalam, diameter 3-5 cm. Di dalam buah terdapat biji yang berbentuk bulat dan apabila sudah matang warna hitam. Pohon aren akan mencapai tingkat kematangan pada umur 6-12 tahun. Kondisi penyadapan terbaik pada umur 8-9 tahun saat mayang bunga sudah keluar. Penyadapan dapat dilakukan pagi dan sore, setiap tahun dapat disadap 3-12 tangkai bunga dengan hasil rata-rata 6,7 liter/hari atau sekitar 900-1600 liter/pohon/tahun. Kualitas nira terbaik bila kadar sukrosa tinggi. (Balitka 1992). Menurut Effendi (2009) tanaman aren dapat tumbuh dengan baik di dekat pantai sampai pada dataran tinggi $1200 \mathrm{~m}$ dari permukaan laut. Tanaman aren sangat cocok pada kondisi landai dengan kondisi agroklimat beragam seperti daerah pegunungan dimana curah hujan tinggi dengan tanah bertekstur liat berpasir. Dalam pertumbuhan tanaman 
ini membutuhkan kisaran suhu $20-25^{\circ} \mathrm{C}$, terutama untuk mendorong perkembangan generatif agar dapat berbunga dan berbuah. Sedang untuk pembentukan mahkota tanaman, kelembaban tanah dan ketersediaan air sangat diperlukan dimana curah hujan yang dibutuhkan antara 1200$3500 \mathrm{~mm} /$ tahun agar kelembaban tanah dapat dipertahankan.

\section{Areal Tanam}

Pada tahun 2014 total areal tanaman aren di Sumatera Utara tercatat seluas 5.297 ha dengan produksi 3.357 ton (Disbun Sumut 2015). Luas areal tanaman aren selama 5 tahun terakhir berdasarkan data yang tersedia bertambah $2,0 \%$ per tahun sedangkan produksi meningkat $1,8 \%$ per tahun. Menurut Rumokoi (2004) data ini perlu diverifikasi karena aren sebagian besar belum dibudidayakan dan penambahan areal baru belum ada kejelasan.

Hasil survei Manoi dan Wardiana (1990) di Jawa Barat untuk kategori tanaman menghasilkan jumlahnya menurun rata-rata pertahun $1,76 \%$, tanaman belum menghasilkan meningkat $4,7 \%$, Sedang tanaman tua/rusak meningkat tajam $20,8 \%$. Dilihat dari jumlah yang ada, proporsi tanaman menghasilkan 54\%, tanaman belum menghasilkan $40 \%$, dan tanaman tua/rusak 6\% memperjelas bahwa areal tanaman aren yang ada di daerah ini sekitar 13.135 ha tidak bertambah bahkan menurun sejak tahun 1980.

Data perkiraan luas tanaman aren saat ini kurang tepat jika menggunakan hanya luas areal. Sebab antar petani di setiap daerah tidak sama kepadatan per hektar. Di Sumatera kepadatan tanaman 5-164 pohon/ha, di Sulawesi Utara menurut Kindangen et al. (1991) 3-120 pohon/ha, sedang di Papua 7-75 pohon/ha (Akuba, 1993). Kepadatan populasi tanaman aren sebaiknya dilakukan berdasarkan data jumlah populasi aren. Umumnya tanaman aren banyak yang tumbuh di kawasan hutan sehingga populasi aren dapat dilakukan dengan menghitung luas kawasan hutan dikali dengan kepadatan populasi aren.
Umumnya tanaman aren banyak yang tumbuh di kawasan hutan sehingga populasi aren dapat dilakukan dengan menghitung luas kawasan hutan dikali dengan kepadatan populasi aren.

Tercatat 20 kabupaten di Sumatera Utara yang memiliki data luas areal tanam aren yang terdiri dari tanaman belum menghasilkan 1.262 ha, tanaman menghasilkan 3.318 ha dan tanaman tidak menghasilkan 717 ha serta data produksi 3.357 ton.

\section{STATUS TEKNOLOGI}

\section{Seleksi pohon induk}

Beberapa hasil penelitian yang sudah dihasilkan dan dapat diterapkan dalam budidaya

pengembangan tanaman aren untuk menambah potensi hasil nira bagi kebutuhan energi terbarukan seperti bioetanol dapat dilakukan dengan cara sebagai berikut : Seleksi Pohon Induk Penentuan blok penghasil tinggi sebagai awal kegiatan seleksi pohon induk dapat dilakukan melalui pengujian keragaman sifat tandan, bunga dan buah. Sifat-sifat tandan, bunga dan buah yang diamati adalah : 1) Jumlah tandan bunga jantan/pohon, 2) Jumlah tandan bunga betina/pohon, 3) Jumlah tandan buah/pohon, 4) Jumlah buah/tandan. Dalam seleksi blok ini keadaan pertanaman seragam dengan bentuk mahkota tegak, bebas hama dan penyakit, terletak di areal pertanaman dan mudah dijangkau. Pohon contoh ditentukan secara acak, kemudian dihitung jumlah tandan bunga jantan, betina dan buah. Pengambilan contoh sebesar 10 persen dari populasi tanaman yang ada. Dalam seleksi pohon induk, pohon yang terpilih berumur > 10 tahun karena pohon yang berumur di bawah 10 tahun produksi niranya belum stabil, sedangkan pohon yang berumur lebih dari 20 tahun kemampuan berproduksinya menurun. Pohon induk yang terpilih ditetapkan produksi niranya lebih dari 10 liter/pohon/tahun. Benih yang akan digunakan berasal dari seleksi buah yang masak dan bebas dari gerekan hama. Dalam 
rangka mendapatkan jumlah mayang/bunga jantan untuk keperluan hasil nira korelasi fenotipik jumlah daun dan panjang tangkai daun mempunyai korelasi nyata pada taraf 1 \%. (Tampake dan Wardiana, 1994).

\section{Perkecambahan dan pembibitan}

Benih dikecambahkan pada wadah perkecambahan dengan media tanah pasir dan pupuk kandang. Dari beberapa hasil penelitian, perkecambahan benih aren telah berhasil dengan daya berkecambah di atas $90 \%$. Suatu cara atau metode yang dapat dipakai untuk menghasilkan daya kecambah benih aren yang tinggi adalah benih yang telah dibersihkan dari daging buah langsung dibenamkan 1-2 cm. Benih yang telah berkecambah (ditandai seperti jaringan spons wadah putih) selanjutnya membentuk apokol sepanjang $12 \mathrm{~cm}$ ke dalam media dan dari ujung apokol keluar akar dan tunas (Mailangkay et al. 2004). Hasil penelitian Hadipoentyanti dan Luntungan (1988) menunjukkan daya kecambah benih yang terbaik apabila benih dikikis dahulu pada bagian titik tumbuh. Penelitian yang sama dihasilkan oleh Saefudin dan Manoi (1994) dimana perlakuan pengikisan bagian titik tumbuh menghasilkan daya tumbuh tertinggi setelah disemai 5

bulan.

Setelah benih aren berkecambah mencapai tinggi 3-5 $\mathrm{cm}$ dapat dipindahkan ke tempat pembibitan (bedeng pembibitan) pada sore hari untuk menghindari penguapan air. Bibit juga dapat dipindahkan ke dalam polybag yang berdiameter 25-40 $\mathrm{cm}$. Tanah yang digunakan dicampur dengan pupuk kandang dengan perbandingan 1:2, dan diisi $3 / 4$ bagian kantong polibag. Bibit aren memerlukan penyiraman dan naungan (atap peneduh) yang tingginya sekitar $1 \mathrm{~m}$ agar terhindar dari cahaya matahari secara langsung.

\section{Penanaman dan penyiangan}

Setelah bibit berumur 1-2 tahun tanaman, dipindahkan ke lokasi penanaman/kebun, dengan membuat lubang tanam ukuran $50 \times 50 \times 50 \mathrm{~cm}$ atau $60 \times 60$ x $60 \mathrm{~cm}$. Di dalam penggalian lubang perlu dipisahkan antara lapisan tanah atas dan tanah lapisan bagian bawah. Setelah lubang digali, biasanya dibiarkan selama 1-2 bulan. Hal ini dimaksudkan untuk menghilangkan gas-gas yang bersifat racun didalam tanah. Sebelum tanah dikembalikan ke dalam lubang perlu dicampur dengan pupuk kandang. Pengajiran dan pembuatan lubang tanam sebaiknya dilakukan diawal musim hujan. Penyiangan perlu dilakukan agar tidak terjadi persaingan di dalam pertumbuhan tanaman aren dengan gulma. Sambil melakukan penyiangan, lakukan juga penggemburan tanah di sekeliling batang aren sekitar 1-1,5 m agar aerasi udara yang akan masuk dan keluar di dalam tanah berlangsung dengan baik.

\section{Pemupukan}

Biasanya setelah melakukan penyiangan, dilanjutkan dengan kegiatan pemupukan pada tanaman. Pemupukan sebaiknya dilakukan 2 kali dalam setahun. Menurut Maliangkay et.al., (2000) pemberian pupuk organik berupa kotoran hewan pada bibit aren dapat memberikan pengaruh yang baik terhadap pertumbuhan bibit aren yang diusahakan. Biaya pemupukan akan semakin berkurang karena tidak hanya bergantung pada pupuk buatan tetapi adanya kombinasi antara pupuk buatan dan bahan organik yang memberikan hasil yang baik. Pemberian pupuk kandang akan memperbaiki sifat fisik dan kimia dari lahan yang digunakan serta dosis yang akan diberikan. Takaran pupuk untuk bibit aren untuk bulan 1 diberikan urea $10 \mathrm{~g}$ dan pupuk kandang

$250 \mathrm{~g}$, untuk bulan ke 2 sebanyak $10 \mathrm{~g}$ urea, dan selanjutnya bulan ke-3 sampai dipindahkan

kelapangan 20 g urea. Khusus untuk umur 1 tahun dan seterusnya pemupukan mengikuti dosis pemberian NPK yaitu $3 \mathrm{~kg}$ $\mathrm{NPK} /$ tanaman/tahun dengan persentase $25 \%$ dosis untuk 1 tahun, $50 \%$ dosis untuk 2 tahun, 75\% dosis untuk 3 tahun, $100 \%$ dosis untuk 4 tahun dan seterusnya. Pemberian 2 kali setahun pada awal dan 
akhir musim hujan. Populasi per hektar 100 tanaman atau jarak tanam $10 \times 10 \mathrm{~m}$ segi empat.

\section{Pengendalian Hama dan Penyakit}

Hama dan penyakit tanaman aren sampai saat ini belum banyak diketahui. Hal ini disebabkan oleh belum dibudidayakannya tanaman aren secara intensif oleh masyarakat sehingga belum ada perhatian khusus terhadap perawatan tanaman aren. Hama seperti Oryctes rhinoceros dan Rhynchoporus sp menyerang pucuk pohon sampai masuk kedalam batang atas dan menembus pangkal pelepah daun muda.Jaringan muda digerek, cairannya diisap. Pada daun bekas gerekan terlihat seperti terpotongpotong. Pengendalian

\section{PROSPEK PENGEMBANGAN TANAMAN AREN}

\section{Potensi Lahan}

Aren menjadi salah satu komoditas unggulan perkebunan Sumatera Utara selain kelapa sawit, karet, kopi, kelapa dan kakao. Pengembangan komoditas ini terus dilakukan sehingga produksinya bisa meningkat dan memberikan kontribusi bagi perekonomian petaninya. Berdasarkan data secara : (1) Mekanik dengan menebang pohon, kemudian dibakar (2) Kimia, pada pucuk pohon diberi Heptachlor sebanyak 10 gram (3) Biologi dengan menggunakan cendawan Metarhizium anisopliae yang dapat menyerang tanaman aren. Dari segi penyakit kebanyakan tanaman aren disebabkan oleh cendawan Helminthosporium. Akibat serangannya daun cepat mengering sehingga mempengaruhi pertumbuhan bibit. Pada permukaan daun yang masih muda bagian atas dan bawah daun muncul bercak-bercak kecil berwarna hijau mengkilat yang selanjutnya membesar dan berubah warna menjadi coklat dengan bagian tepi terdapat lingkaran kuning.

Dinas Perkebunan Sumut, produksi aren per tahun 2015 mencapai 3.233,25 ton dengan lahan seluas 5.288,91 hektare. Lebih rinci luas tanam dan produksi aren tanaman perkebunan tanaman rakyat menurut kabupaten, dapat dilihat pada tabel 1 di bawah ini.

Tabel 1. Luas tanam dan produksi aren tanaman perkebunan tan. rakyat menurut kabupaten

\begin{tabular}{|c|c|c|c|c|c|}
\hline \multirow[t]{2}{*}{ Kabupaten } & \multicolumn{4}{|c|}{ Luas tanam (ha) } & \multirow[t]{2}{*}{ Total } \\
\hline & $T B M$ & $T M$ & TTM & Jumlah & \\
\hline 1. Nias & 3 & 7 & - & 10 & 4 \\
\hline 2. Mandina & 119 & 430 & 140 & 689 & 700 \\
\hline 3. Tapsel & 98 & 266 & 85 & 449 & 154 \\
\hline 4. Tapteng & 4 & 48 & 7 & 59 & 59 \\
\hline 5. Taput & 166 & 270 & 55 & 491 & 261 \\
\hline 6. Tobasa & 71 & 141 & 35 & 247 & 98 \\
\hline 7. Lab. Batu & 4 & 4 & - & 8 & 4 \\
\hline 8. Simalungun & 4 & 634 & 60 & 689 & 610 \\
\hline 9. Dairi & 23 & 43 & 2 & 68 & 40 \\
\hline 10. Karo & 90 & 47 & 145 & 705 & 470 \\
\hline 11. Deli Serdang & 148 & 340 & 15 & 503 & 371 \\
\hline 12. Langkat & 41 & 110 & 11 & 162 & 93 \\
\hline 13. Humbahas & 45 & 157 & 26 & 228 & 143 \\
\hline 14. Samosir & 116 & 118 & 12 & 246 & 123 \\
\hline 15. Sergei & 3 & 12 & 1 & 16 & 14 \\
\hline 16. Paluta & 119 & 140 & 10 & 269 & 132 \\
\hline
\end{tabular}




\begin{tabular}{llllll}
\hline 17. Palas & 193 & 88 & 100 & 281 & 53 \\
18. Lab. Selatan & 4 & 4 & - & 8 & 4 \\
19. Nias Utara & 14 & 39 & 13 & 66 & 36 \\
20. Nias Barat & 1 & 1 & - & 2 & 1 \\
\hline
\end{tabular}

Sumber : Dinas Perkebunan Provinsi Sumatera Utara 2015.

Tanaman aren yang eksis di Sumatera Utara hampir dijumpai di setiap kabupaten. Menurut data Disbun Sumut 2014, lima kabupaten yang memiliki luas tanam terbesar yaitu Kabupaten Karo 705 ha, Simalungun 698 ha, Madina 689 ha Deli Serdang 503 ha dan Tapanuli Utara 491 ha. Salah satu contoh kabupaten yang mempunyai prospek potensi pengembangan aren adalah Kabupaten Pakpak Bharat (data tidak tercatat pada tabel 1 diatas) dimana dari data tata guna lahan tercatat 11.863 ha lahan sementara tidak diusahakan dan juga lahan hutan rakyat 3.988 ha serta lahan alang-alang/kritis yang dapat termanfaatkan untuk pengembangan aren. Hal ini apabila disurvei ke kabupaten lain tidak tertutup kemungkinan banyak lahanlahan yang mempunyai peluang dan potensi pengembangan aren. Prospek potensi pengembangan aren di Sumatera Utara cukup besar, hal ini dapat di lihat dari ekosistem, iklim dan kesesuaian lahan yang ada di masing-masing kabupaten yang cukup mendukung untuk tanaman aren.

Kelas kesesuaian lahan untuk aren sesuai persyaratan penggunaan / karakteristik lahan dibedakan menjadi S1 (sangat sesuai) S2 (cukup sesuai) S3 ( sesuai marginal) dan N (tidak sesuai). Rata-rata temperatur berkisar antara $15-40^{\circ} \mathrm{C}$ yang optimim antara 22 $28^{0} \mathrm{C}$. Curah hujan berkisar antara $750-2.500$ $\mathrm{mm} /$ tahun dengan bulan kering mencapai antara 3-6 bulan. Persyaratan kebutuhan tanah sebagai berikut : dapat tumbuh pada berbagai tipe tanah, kedalaman minumum 50 $\mathrm{cm}$, kosistensi gembur (lembab), permeabilitas sedang, drainase baik, reaksi tanah $(\mathrm{pH})$ berkisar antara 4,5 - 8,2 yang optimum 5,5 - 7,8 (Djaenudin dkk. 2000). Luas lahan yang sementara (lahan tidur) di tidak diusahakan di Sumatera Utara sejak tahun 2009 - 2013 cenderung meningkat sampai tahun 2013 seluas 296.032 ha
(Pusdatim Pertanian 2014). Apabila lahan seluas itu (lahan tidur) temanfaatkan minimal $30 \%$ saja maka diperoleh sekitar 8 jutaan tanaman aren yang bisa dikembangkan. Sehingga perlu suatu kebijakan dari masingmasing Pemerintah Daerah untuk membuat suatu seperti Peraturan Daerah (Perda) untuk mengatur lahan-lahan yang tidak termanfaatkan.

suatu keberhasilan pengembangan pertanaman ditentukan oleh lingkungan dimana komoditas itu dikembangkan. Agro ekosistem atau faktor biofisik seperti tanah dan iklim menjadi peluang atau kendala dalam pembangunan komoditas tersebut. Keberhasilan pembangunan pertanian sangat tergantung pada kemampuan petani atau pelaku agribisnis penerapkan teknologi yang ada dengan memanfaatkan sumberdaya alam. (Departemen Pertanian 2006). Indonesia menurut Mulyani dan Las (2008) memiliki sumberdaya lahan yang luas untuk pengembangan komoditas pertanian.

\section{PELUANG DAN TANTANGAN}

\section{Peluang}

Peluang tanaman aren dapat dengan mudah beradaptasi pada berbagai tipe tanah yang diusahakan untuk komoditas pertanian termasuk tanah marginal, selain itu tanaman ini berfungsi untuk konservasi tanah dan air. Peluang dan potensi pengembangan aren di Sumatera Utara mempunyai prospek cukup baik dimana di masing-masing kabupaten/kota memiliki ekosistem, iklim dan kesesuaian lahan yang mendukung. Selain itu, lahan yang tidak diusahakan baik sementara maupun permanen masih cukup luas juga lahan marginal, alang-alang, hutan rakyat dan lain-lain yang semuanya itu bisa termanfaatkan untuk tanaman aren. Sebagian 
besar pertanaman aren belum menerapkan inovasi teknologi yang ada. Sehingga adanya diseminasi teknologi akan membawa dampak bukan hanya produktivitas dan pendapatan petani, tetapi berkembangnya diversifikasi hasil yang memberi kesempatan usaha dan lapangan kerja bagi banyak orang. Ketersediaan teknologi walaupun belum lengkap telah dilakukan berbagai kegiatan penelitian untuk menunjang agribisnis aren. Teknologi yang sudah siap pakai meliputi: pemilihan pohon induk tanaman, pesemaian, pembibitan, budidaya, penyadapan, pengawetan nira, pengolahan gula, gula semut, gula kristal, pengolahan pati aren dan pembuatan etanol. Cadangan lahan yang tersedia disetiap kabupaten/kota termasuk lahan kritis, padang alang, dan lain-lain dapat ditanami tanaman aren. Adanya gerakan nasional rehabilitasi hutan dan lahan dapat mempergunakan tanaman aren untuk program konservasi dan reboisasi.

\section{Tantangan}

Masalah utama pengembangan aren : input teknologi sangat minim, managemen produksi, pengolahan dan pemasaran masih cara tradisional; diseminasi teknologi belum mencapai sebagian besar petani; dampak negatif produksi aren sebagai minuman keras. Kesulitan dalam penyediaan benih/bibit unggul.

Selain itu ada banyak lahan tidur yang tidak termanfaatkan karena beberapa alasan utama, beberapa diantaranya adalah: (1) lahan dalam skala besar yang telah terlanjur dikuasai oleh pemegang HGU tidak layak untuk diusahakan dikarenakan kondisi tanah dan topografi yang berat; (2) pemegang HGU mengalami kesukaran finasial untuk mengelola lahan yang dikuasainya; (3) lahan skala lebih kecil yang dikuasai masyarakat yang tidak dimanfaatkan; (4) lahan tidur tersebut masih berstatus lahan negara tetapi tidak dimanfaatakn untuk tujuan produktif.

Sampai saat ini belum ada varietas yang dilepas, benih yang ada diambil dari Blok Penghasil Tinggi (BPT) yang diseleksi berdasarkan seleksi individu terbaik populasi tersebut. Penggunaan tanaman aren dari kegiatan reboisasi hanya untuk zona penyangga dan kegiatan penghijauan oleh Dinas/Instansi untuk konservasi tetapi belum memberdayakan petani sehingga tanaman tersebut belum mempunyai nilai tambah (Ardi 2004). Kemampuan sumber daya manusia, petugas dan petani terbatas karena hasil-hasil diseminasi inovasi teknologi dari lembagalembaga yang berkompetensi tidak sampai kepada pemakai/konsumen.

\section{SIMPULAN DAN IMPLIKASI}

Perlu kebijakan dari Pemerintah Pusat dan Daerah untuk membuat suatu peraturan yang mengatur pemanfaatan lahan-lahan yang sementara/permanen tidak diusahakan, supaya termanfaatkan untuk pengembangan tanaman aren yang kedepannya mempunyai nilai ekonomi yang cukup menjanjikan. Tanaman aren berpeluang untuk dijadikan tanaman penghasil bioetanol karena daya adaptasi terhadap berbagai kondisi lahan dan agroklimat. Tersedia inovasi teknologi untuk mengembangkan tanaman aren sebagai penghasil meliputi: sumber benih, budidaya, penyadapan nira dan pengolahan nira menjadi bioetanol. Namun demikian untuk tidak menjadi saingan bahan pangan disarankan pengembangan aren diarahkan dalam bentuk pengembangan areal baru khusus untuk bioetanol dengan orientasi pilot projek pada propinsi dan kabupaten yang berminat. Sesuai dengan kebutuhan nasional telah dicanangkan 6,4 juta hektar selama 2005-2015 untuk tanaman penghasil bioetanol termasuk untuk aren.

Tantangan ke depan bagi pengembangan tanaman aren bukan hanya untuk sumber pangan, tetapi dapat dijadikan sumber bioetanol dan diversifikasi produk lainnya dalam upaya

peningkatan pendapatan dan konservasi lahan. Diperlukan pilot project yang terpadu dengan aplikasi inovasi teknologi terkini yang berorientasi agribisnis. Komitmen pelaksanaan diserahkan kepada provinsi/ 
kabupaten untuk membiayai, melaksanakan, dan monitoringnya. Penelitian aren untuk menghasilkan bioetanol oleh Badan Litbang Pertanian harus mendapatkan prioritas utama. Kegiatan ini harus dirancang dalam bentuk penelitian aren jangka pendek dan panjang yang jelas dapat memberikan hasil konkrit dalam pengembangan tanaman aren dengan kawasan pelestarian lingkungan.

\section{DAFTAR PUSTAKA}

Akuba, R.H. 1993. Prospek Pengembangan Aren di Irian Jaya. Balitka Dok.420/VIII/93.

Alam, S. dan D. Baco.2004. Peluang Pengembangan dan Pemanfaatan Tanaman Aren di Sulawesi Selatan. Pengembangan Tanaman Aren. Prosiding Seminar Nasional Aren. Tondano. Balai Penelitian Tanaman Kelapa dan Palma Lain, 9 Juni hlm.15-21.

Ardi, H. 2004. Tantangan dan Peluang Pengembangan Aren di Propinsi Kalimantan TengahPengembangan Tanaman Aren. Prosiding Seminar Nasional Aren. Tondano, 9 Juni 2004. Balai Penelitian Tanaman Kelapa dan Palma Lain. hlm.44-57.

Balitka. 1992. Prospek Tanaman Kelapa, Aren, Lontar dan Gewang Untuk Menghasilkan Gula. Media Komunikasi Penelitian dan Pengembangan Tanaman Industri. hlm. 37-40.

Disbun Sumatera Utara, 2015. Statistik Perkebunan Sumatera Utara.

Ditjenbun, 2006. Teknik Budidaya Tanaman Aren.

Djaenudin, D., Marwan H., H. Subagyo, Anny, M., N. Suharta. 2000. Kriteria Kesesuaian Lahan untuk Komoditas Pertanian. Pusat Penelitian Tanah dan Agroklimat. Badan Penelitian dan Pengembangan Pertanian. Versi 3. September 2000. 264 hal.

Effendi, D.S. 2009. Aren, Sumber Energi Alternatif. Warta Penelitian dan
Pengembangan Pertanian. Tahun 2009. 31(2):1-3.

Hadipoentyanti, E. dan H. Luntungan. 1988. Pengaruh Beberapa Perlakuan Terhadap Perkecambahan Biji Aren (Arenga pinnata MERR). Jurnal Penelitian Kelapa 2(2):20-25.

Heyne, K. 1987. Tumbuhan Berguna Indonesia. Yayasan Sarana Wana Jaya. Departemen Kehutanan Republik Indonesia, Jakarata, hal. 918920.

Kindangen, J.G., Jefri, N.M. Mokodongan dan H. Hasni. 1991. Potensi dan Sebaran Tanaman Aren di Sulawesi Utara. Buletin Balitka 14 : 83-89.

Maliangkay, R.B., Yulianus Matana, Novalisa Lumentut, dan E. Manaroinsong. 2004. Budidaya Tanaman Aren. Pengembangan Tanaman Aren. Prosiding Seminar Nasional Aren Tondano, 9 Juni 2004. Balai Penelitian Tanaman Kelapa dan Palma Lain. hlm.131-137.

Maliangkay, R.B., D. Allorerung dan M. Polnaya. 2000. Pengaruh Pupuk Organik dan AnOrganik

Terhadap Pertumbuhan Bigit Aren. Buletin Palma No. 26. Balitka Manado.

Manoi, F. dan E. Wardiana. 1990. Perkembangan Luas Areal dan Poduksi Gula Aren di Jawa Barat. Buletin Balitka 11. hlm 92 - 96.

Pusdatim Kementan 2014. Stastik Lahan Pertanian 2009 - 2013. 185 hal.

Ramadhani, R. 2015. Potensi dan Manfaat Ekonomi dari Pohon Aren (Arenga pinnata Merr). Makalah Ekonomi Sumber Daya Hutan Medan, April 2015.

Rindengan, B dan E.Manaroinsong. 2009. Aren. Tanaman Perkebunan Penghasil Bahan Bakar Nabati (BBM). Pusat penelitian dan Pengembangan Perkebunan. hlm.1-22.

Rumokoi, M.M.M. 2004. Aren, Kelapa dan Lontar Sebagai Alternatif Pemenuhan Kebutuhan Gula Nasional. Prosiding Seminar Nasional Aren. Tondano. 
Balai Penelitian Tanaman Kelapa dan Palma Lain. 9 Juni.

Saefudin dan F. Manoi. 1994. Pengaruh Perlakuan Benih dan Media Tumbuh Terhadap Perkecambahan Benih Aren. Forum Komunikasi penelitian kelapa dan palma. Sub Balai Penelitian Kelapa Pakuwon.Hlm.96-100.

Smith, W. 2014. Ada 65 Manfaat Pohon Aren Termasuk Bioethanol Pengganti BBM dan Gula.Yayasan Masarang.

Soeseno, S. 1991. Bertanam Aren. P.T. Penebar Swadaya, Jakarta.

Sunanto, H. 1992. Aren (Budidaya dan Multigunanya). Kanisius. Yogyakarta Syakir dan D.S. Effendi. 2010. Prospek Pengembangan Tanaman Aren (Arenga pinnata MERR) untuk Bioetanol, Peluang dan Tantangan. Makalah disajikan dalam Workshop Peluang, Tantangan dan Prospek Pengembangan Aren untuk 46 Volume 9 Nomor 1, Juni 2010 : 36 46 Bioetanol Skala Industri dan UMKM, Hotel Salak Bogor 21 Januari 2010. hlm.17.

Tampake, H dan E. Wardiana. 1994. Studi karakter Aren di kabupaten Cianjur Jawa Barat. Buletin Balitka. Balai Penelitian Kelapa Manado. hlm.53-57.

Akuba, R.H. 1993. Prospek Pengembangan Aren di Irian Jaya. Balitka Dok.420/VIII/93.

Alam, S. dan D. Baco.2004. Peluang Pengembangan dan Pemanfaatan Tanaman Aren di Sulawesi Selatan. Pengembangan Tanaman Aren. Prosiding Seminar Nasional Aren. Tondano. Balai Penelitian Tanaman Kelapa dan Palma Lain, 9 Juni hlm.15-21.

Ardi, H. 2004. Tantangan dan Peluang Pengembangan Aren di Propinsi Kalimantan Tengah Pengembangan Tanaman Aren. Prosiding Seminar Nasional Aren. Tondano, 9 Juni 2004. Balai Penelitian Tanaman Kelapa dan Palma Lain. hlm.44-57.

Balitka. 1992. Prospek Tanaman Kelapa, Aren, Lontar dan Gewang Untuk
Menghasilkan Gula.

Media

Komunikasi Penelitian dan Pengembangan Tanaman Industri. hlm. 37-40.

Disbun Sumatera Utara, 2015. Statistik Perkebunan Sumatera Utara.

Ditjenbun, 2006. Teknik Budidaya Tanaman Aren.

Djaenudin, D., Marwan H., H. Subagyo, Anny, M., N. Suharta. 2000. Kriteria Kesesuaian Lahan untuk

Komoditas Pertanian. Pusat Penelitian Tanah dan Agroklimat. Badan Penelitian dan Pengembangan Pertanian. Versi 3. September 2000. 264 hal.

Effendi, D.S. 2009. Aren, Sumber Energi Alternatif. Warta Penelitian dan Pengembangan Pertanian.

Tahun 2009. 31(2):1-3.

Hadipoentyanti, E. dan H. Luntungan. 1988. Pengaruh Beberapa Perlakuan Terhadap Perkecambahan Biji Aren (Arenga pinnata MERR). Jurnal Penelitian Kelapa 2(2):20-25.

Heyne, K. 1987. Tumbuhan Berguna Indonesia. Yayasan Sarana Wana Jaya. Departemen Kehutanan Republik Indonesia, Jakarata, hal. 918920.

Kindangen, J.G., Jefri, N.M. Mokodongan dan H. Hasni. 1991. Potensi dan Sebaran Tanaman Aren di Sulawesi Utara. Buletin Balitka 14 : 83-89.

Maliangkay, R.B., Yulianus Matana, Novalisa Lumentut, dan E. Manaroinsong. 2004.

Budidaya Tanaman Aren. Pengembangan Tanaman Aren. Prosiding Seminar Nasional Aren Tondano, 9 Juni 2004. Balai Penelitian Tanaman Kelapa dan Palma Lain. hlm.131-137.

Maliangkay, R.B., D. Allorerung dan M. Polnaya. 2000. Pengaruh Pupuk Organik dan AnOrganik Terhadap Pertumbuhan Bigit Aren. Buletin Palma No. 26. Balitka Manado. 
Manoi, F. dan E. Wardiana. 1990. Perkembangan Luas Areal dan Poduksi Gula Aren di Jawa Barat. Buletin Balitka 11. hlm 92 - 96.

Pusdatim Kementan 2014. Stastik Lahan Pertanian 2009 - 2013. 185 hal.

Ramadhani, R. 2015. Potensi dan Manfaat Ekonomi dari Pohon Aren (Arenga pinnata Merr). Makalah Ekonomi Sumber Daya Hutan Medan, April 2015.

Rindengan, B dan E.Manaroinsong. 2009. Aren. Tanaman Perkebunan Penghasil Bahan Bakar Nabati (BBM). Pusat penelitian dan Pengembangan Perkebunan. hlm.1-22.

Rumokoi, M.M.M. 2004. Aren, Kelapa dan Lontar Sebagai Alternatif Pemenuhan Kebutuhan Gula Nasional. Prosiding Seminar Nasional Aren. Tondano. Balai Penelitian Tanaman Kelapa dan Palma Lain. 9 Juni.

Saefudin dan F. Manoi. 1994. Pengaruh Perlakuan Benih dan Media Tumbuh Terhadap Perkecambahan Benih Aren. Forum Komunikasi penelitian kelapa dan palma. Sub Balai Penelitian Kelapa Pakuwon.Hlm.96-100.Smith, W. 2014. Ada 65 Manfaat Pohon Aren Termasuk Bioethanol Pengganti BBM dan Gula.Yayasan Masarang.

Soeseno, S. 1991. Bertanam Aren. P.T. Penebar Swadaya, Jakarta.

Sunanto, H. 1992. Aren (Budidaya dan Multigunanya). Kanisius. Yogyakarta

Syakir dan D.S. Effendi. 2010. Prospek Pengembangan Tanaman Aren (Arenga pinnata MERR) untuk Bioetanol, Peluang dan Tantangan. Makalah disajikan dalam Workshop Peluang, Tantangan dan Prospek Pengembangan Aren untuk 46 Volume 9 Nomor 1, Juni 2010 : $36-46$ Bioetanol Skala Industri dan UMKM, Hotel Salak Bogor 21 Januari 2010. hlm.17.

Tampake, H dan E. Wardiana. 1994. Studi karakter Aren di kabupaten Cianjur Jawa Barat. Buletin Balitka. Balai Penelitian Kelapa Manado. hlm.53-57. 
Vol.3, No.2. Agustus 2016. (15) : 133- 138 